TITLE:

\title{
Planuloid budding from a cutting plane of polyp stalk of Cassiopea sp.(Cnidaria, Scyphozoa)
}

$\operatorname{AUTHOR}(S)$ :

Niina, Kazuhito; Gravili, Cinzia; Kubota, Shin

\section{CITATION:}

Niina, Kazuhito ... [et al]. Planuloid budding from a cutting plane of polyp stalk of Cassiopea sp.(Cnidaria, Scyphozoa). Publications of the Seto Marine Biological Laboratory 2015, 43: 103-105

ISSUE DATE:

2015-09-15

URL:

http://hdl.handle.net/2433/199853

RIGHT: 
Publ. Seto Mar. Biol. Lab., 43: 103-105, 2015

\title{
Planuloid budding from a cutting plane of polyp stalk of Cassiopea sp. (Cnidaria, Scyphozoa)
}

\author{
KAZUHITO NIINA*, CINZIA GRAVILI ${ }^{* *}$ AND SHIN KUBOTA* $^{*}$ \\ *Seto Marine Biological Laboratory, Field Science Education and Research Center, Kyoto University \\ Shirahama-cho 459, Nishimuro, Wakayama Prefecture 649-2211, Japan \\ E-mail: kubota.shin.5e@kyoto-u.ac.jp \\ ** Department of Biological and Environmental Science and Technology (Di.S.Te.B.A.), University of Salento \\ 73100 Lecce, Italy
}

\begin{abstract}
Cassiopea polyps that appeared in culture vessels of Turritopsis sp. polyps at the Seto Marine Biological Laboratory, Kyoto University in 2014 were experimentally amputated their stalks from the calyxes. On the cutting plane, planuloid buds were exclusively produced and stalks were never regenerated. Planuloids became polyps but some of them were never produced stalks. It is assumed that the polyp that accidentally lost its stalk has a chance to raise their survival rate by releasing multiple of planuloids.
\end{abstract}

Keywords: amputation experiment, calyx, Cassiopea polyp, planuloid, stalk

\section{Introduction}

Cassiopea sp. (Cnidaria, Scyphozoa) is well-known in its unique posture on the seabed with an upside down form of ordinal jellyfish. This medusa inhabits mainly in tropical sea, and in Japan it is distributed over south of southern Kyushu and does not appear around Honshu (Miyake and Lindsay, 2013; Kubota, 2014). Cassiopea produces planulae by sexual reproduction as an ordinary medusa. It is also known that it is propagated by producing planuloids from a calyx (Uchida, 1961; Curtis and Cowden, 1971, 1972; Hofmann et al., 1978; Miyake and Lindsay, 2013).

Recently more than 15 Cassiopea polyps suddenly appeared in culture vessels of Turritopsis sp. polyps at the Seto Marine Biological Laboratory, Field Science Education and Research Centre, Kyoto University in July 2013 (Fig. 1). One individual of the Cassiopea polyps was accidentally injured between its stalk and calyx. It is then amputated itself. Planuloids were produced and released one after another from the calyx of this polyp without stalk. The polyp that lost its stalk did not regenerate this structure, but reproduced asexually as a unique method. Therefore we carried out an amputation experiment and reported these results.

\section{Material and Methods}

By releasing ephyrae we were able to confirm that these scyphopolyps (Fig. 1) were one of the species of Cassiopea (although not to species level) that we did not have any records of witness or capture in the area of seacoast at Shirahama, Wakayama Prefecture (Kubota, 2014). It is assumed these polyps possibly originated from the planulae carried by the Kuroshio current and had intruded from an external pipe to the aquarium. 


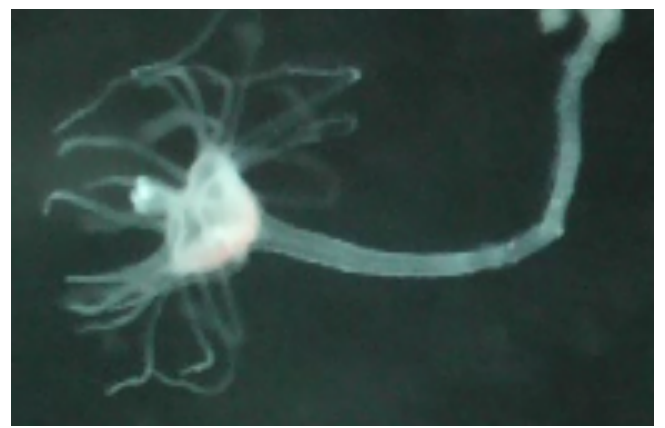

Figure 1. Cassiopea polyp that appeared in a breeding aquarium at the Seto Marine Biological Laboratory, Field Science Education and Research Centre, Kyoto University.

Beginning of August in 2013, three Cassiopea polyps were picked up from culture vessels of Turritopsis sp. (cf. Kubota, 2011) and kept them in a $30 \mathrm{~mm}$ diameter, $15 \mathrm{~mm}$ height polystyrene cylindrical vessel using the stagnant water ( $5 \mu \mathrm{m}$-sieved natural seawater) at $26^{\circ} \mathrm{C}$ and fed them hatched Artemia nauplii. Then they were experimentally amputated their stalks from the calyxes by sharpened stainless needles (Fig. 2, left) and observed the following phenomena for about at least nine months.
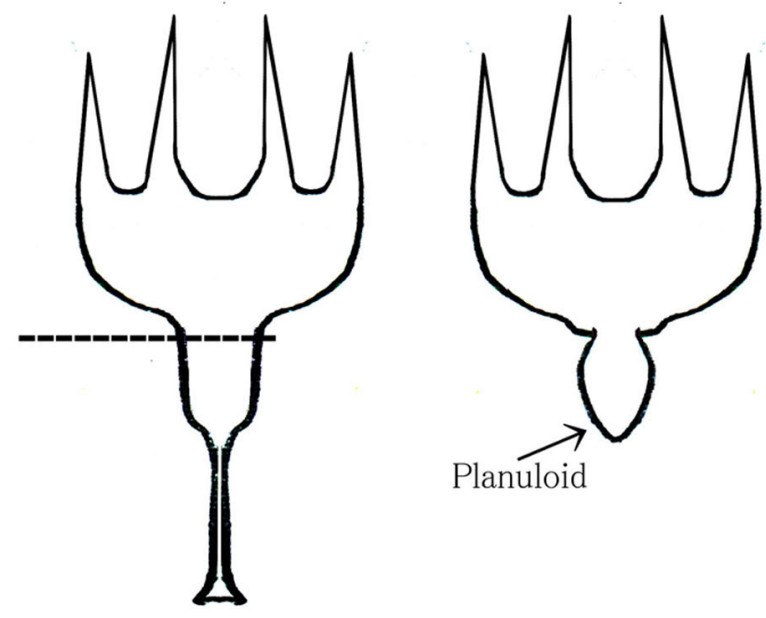

Figure 2. Amputation of Cassiopea sp. polyp between its stalk and calyx (left: amputated at the dashed line) and the budding of a planuloid (right).

\section{Results and Discussion}

Planuloid bud was exclusively produced from a cutting plane of polyp calyx (Fig. 2, right; Fig. 3), and such a budding had never reported elsewhere (Curtis and Cowden, 1972). The lost stalk was never regenerated as described before by Curtis and Cowden (1972). All the free-swimming planuloids attached to a breeding vessel and grew to polyps. These polyps could have been kept at least in May 2015. Not all but some of these grown polyps were never produced stalks. This is partly due to the presence of suitable bacteria film on the rearing vessel as was pointed out by Hofmann et al. (1978).

Normally the planuloid buds at the side of their polyp calyx with stalk (Uchida, 1961; Curtis and Cowden, 1971, 1972; Hofmann et al., 1978; Miyake and Lindsay, 2013), but the buddings observed in the present study were always different, i.e. from a cutting plane of polyp calyx (Fig. 2, right; Fig. 3). Amputated two body 


\section{PLANULOID BUDDING OF CASSIOPEA}

portions, the upper calyx and the lower stalk, never regenerated their lost parts, according to the former observation by Curtis and Cowden (1972) for the calyx but not for the stalk, though sample size is small in the present study.

From these preliminary observations and experiment in four polyps, it is assumed that the polyp that accidentally lost its stalk in the nature have a chance to raise their survival rate by releasing multiple of planuloids, even if their mother body can not completely regenerate.

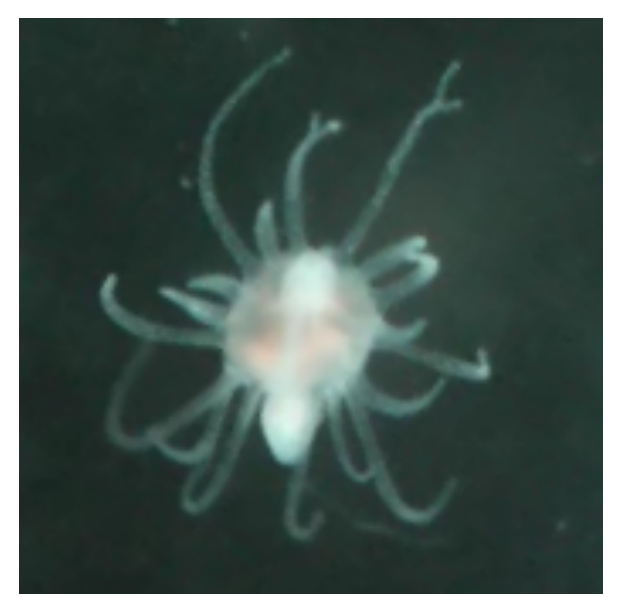

Figure 3. Amputated Cassiopea polyp budded a planuloid from the cutting plane of calyx.

\section{Acknowledgments}

We thank anonymous reviewers for their kind improvement of the manuscript.

\section{Literature cited}

Curtis, S. K. and Cowden, R. R. 1971. Normal and experimentally modified development of buds in Cassiopea (phylum Coelenterata; class Scyphozoa). Acta Embryologiae Experimentalis 3, 239-259.

Curtis, S. K. and Cowden, R. R. 1972. Regenerative capacities of Cassiopea (phylum, Coelenterata; class, Scyphozoa). Acta Embryologiae Experimentalis suppl., 429-454.

Hofmann, D. K., Neumann, R. and Henne, K. 1978. Strobilation, budding and initiation of scyphistoma morphogenesis in the rhizostome Cassiopea andromeda (Cnidaria, Scyphozoa). Marine Biology, 47, 161-176.

Kubota, S. 2011. Repeating rejuvenation in Turritopsis, an immortal hydrozoan (Cnidaria, Hydrozoa). Biogeography, 13, 101-103.

Kubota, S. 2014. Fascinating medusae from warm waters. 167 pp. Kiiminpou, Wakayama, Japan. (In Japanese)

Miyake H. and Lindsay, D. 2013. Recent Encyclopedia of Jellyfish. 127 pp. Seibundo-Shinkosha, Tokyo, Japan.

Uchida, T. 1961. Systematic Zoology 2. 233 pp., Nakayama-Shoten, Tokyo, Japan. (In Japanese)

Received: 17 May 2015

Accepted: 30 August 2015

Published: 15 Sept 2015 